\title{
The place of radioisotopic lung function studies in paediatrics
}

\section{S. GODFREY AND SHEILA McKENZIE}

From the Department of Paediatrics and Neonatal Medicine, Hammersmith Hospital, London

SUMMARY An analysis of the clinical value of radioisotopic lung function (RLF) tests has been carried out on the results of studies in 123 children with heart or lung disease. The overall incidence of useful RLF tests was $53 \%$, but in children between 6 months and 6 years the incidence was higher (69\%). The incidence of useful RLF tests was similar whatever the question to be answered, although rather higher when information about differential pulmonary blood flow was required. Lists of conditions are presented for which the incidence of useful RLF tests is likely to be high (72\%), moderate $(46 \%)$, and low $(14 \%)$.

The use of radioisotopes for studying lung function has been applied to adults for a long time and also, to some extent, in children able to co-operate with adult techniques (Kjellman, 1967; Treves et al., 1974). The indications for radioisotopic lung function (RLF) tests have never been clearly defined and depend upon the physician's enthusiasm and the availability of equipment as much as anything else. In a recent textbook on paediatric nuclear medicine (James et al., 1974) the section on lung scanning recommends the application of RLF (chiefly in the form of labelled macroaggregates) for virtually every paediatric pulmonary and cardiac disorder.

We have previously described the development of a method for studying regional lung function in children of all ages requiring no active co-operation from the child, its application in various pulmonary conditions (Godfrey et al., 1975, 1977; Ronchetti et al., 1975; Winlove et al., 1977) and for the detection of pulmonary vascular disease (McKenzie et al., 1977). Over the past 2 years we have applied the technique in the investigation of 123 children with a variety of disorders. This experience has led us to a clearer understanding of the indications for using RLF tests in children and we now present our conclusions.

\section{Patients}

All the children studied had either pulmonary or cardiac disease which in the opinion of the physician in charge of the patient was of such a nature as to justify RLF testing in order to provide additional

Received 1 April 1977 information about the severity or localization of the disease. The children were aged between one month and 14 years.

\section{Methods}

RLF tests were carried out as described elsewhere (Godfrey et al., 1975; Ronchetti et al., 1975) and the method will only be summarized here. The child lay supine on a couch over a gamma camera and breathed normally throughout the study. Small children were lightly sedated so that they kept still. The isotope used in all but 3 children was radioactive nitrogen $\left({ }^{13} \mathrm{~N}\right)$ which has a half-life of only 10 minutes and was produced for immediate use by the adjacent Medical Research Council Cyclotron Unit. The other children received xenon $\left({ }^{133} \mathrm{Xe}\right)$. The isotope was administered once as an inhalation bolus via a nasal catheter in infants or via a mouthpiece in co-operative children and once as a bolus infusion into a peripheral vein. The arrival and washout of radioactivity in both perfusion and inhalation studies was continuously recorded with a gamma cameracomputer system. Subsequently, the results were corrected for camera nonuniformity, background, and isotope decay, and were then expressed as activity-time curves.

${ }^{13} \mathrm{~N}$ is extremely insoluble and so the inhalation study reflects the distribution and adequacy of clearance of ventilated lung. When injected intravenously, ${ }^{13} \mathrm{~N}$ leaves the blood for the gas as soon as it reaches the alveoli and is then washed out by ventilation. Any delay in washout after perfusion compared with inhalation is thus a measure of ventilation-perfusion imbalance. The results using 
${ }^{133} \mathrm{Xe}$ are similar. 'Normal' ranges of values for regional lung function in children were calculated from 20 normal lung zones in children with known localized disease (Winlove et al., 1977). The total pulmonary radiation received from this type of study is approximately 70 to $180 \mathrm{mrad}$ and the dose to the rest of the body, about 5 to $25 \mathrm{mrad}$. These doses are roughly equivalent to one-third that received by bronchography and 5 to $10 \%$ or less of the whole body dose usually received at cardiac catheterization. An intravenous pyelogram gives a child a skin dose of 200 to $750 \mathrm{mrad}$ and a whole body dose of 30 to $70 \mathrm{mrad}$ (James et al., 1974). For those wishing to use ${ }^{133} \mathrm{Xe}$, the lung dose is about a third, and the whole body dose about double, that of ${ }^{13} \mathrm{~N}$.

Other diagnostic procedures such as bronchography, cardiac catheterization, etc., were performed in the usual manner when indicated for clinical reasons.

\section{Interpretation of data}

The objective of the present study was to determine the clinical importance of RLF in the children who had been studied in good faith with the prior belief that the test would be useful. The clinical and physiological data for each child were considered in terms of the questions posed at the time of the study, and the eventual answers. All the relevant investigations were then considered to determine which, if any, had given the clearest answers to the questions raised at the time of the RLF study. In most children there was only one main question to be answered and only one useful investigation, but sometimes there was more than one question or equally useful investigation so that the totals in the tables of results do not always appear the same. Thus there were 123 children studied to answer 135 questions and there were 152 useful investigations.

\section{Results}

Of the 123 children studied, $13 \%$ were less than 6 months old, $45 \%$ were between 6 months and 6 years old, and $42 \%$ were over 6 years. The clinical categories and proportions of useful RLF tests in each age range are given in Table 1 . It should be noted that this is not a completely random selection of children passing through this department and is somewhat biased by current interests in cystic fibrosis, musculoskeletal deformities, and pulmonary vascular disease. Apart from these groups, the most common diagnostic classification was unilateral radiolucent lung. The miscellaneous group consisted of children with a wide variety of unrelated disorders or suspected lung disease not fitting into the other diagnostic groups listed in Table 1. Among the large cardiac group there were children with many types of congenital heart disease of which the commonest was ventricular septal defect $(57 \%)$ with or without pulmonary hypertension.

The overall incidence of worthwhile RLF studies, i.e. the proportion which gave a definite answer to the diagnostic question, was $53 \%$, and this varied from 0 to $83 \%$ in the different clinical groups (Table 1). They were considered to be of no value in children with bronchiectasis, isolated lung cysts or solid lesions, and inhaled foreign bodies because although the scans were highly abnormal and

Table 1 Diagnostic groups and proportion of useful RLF tests

\begin{tabular}{|c|c|c|c|c|c|c|c|}
\hline \multirow[b]{2}{*}{ Diagnosis } & \multicolumn{2}{|c|}{ Under 6 months } & \multicolumn{2}{|c|}{6 months to 6 years } & \multicolumn{2}{|c|}{ Over 6 years } & \multirow[b]{2}{*}{$\begin{array}{l}\text { Proportion } \\
\text { of useful } \\
\text { tests } \\
(\%)\end{array}$} \\
\hline & $\begin{array}{l}\text { No. of } \\
\text { useful } \\
\text { tests }\end{array}$ & $\begin{array}{l}\text { No. } \\
\text { studied }\end{array}$ & $\begin{array}{l}\text { No. of } \\
\text { useful } \\
\text { tests }\end{array}$ & $\begin{array}{l}\text { No. } \\
\text { studied }\end{array}$ & $\begin{array}{l}\text { No. of } \\
\text { useful } \\
\text { tests }\end{array}$ & $\begin{array}{l}\text { No. } \\
\text { studied }\end{array}$ & \\
\hline \multicolumn{8}{|l|}{ Unilateral } \\
\hline hyperlucent lung & 2 & 4 & 5 & 7 & 1 & 3 & 57 \\
\hline Cystic fibrosis & 0 & 2 & 4 & 4 & 7 & 16 & 50 \\
\hline \multirow{2}{*}{\multicolumn{5}{|c|}{$\begin{array}{l}\text { Congenital heart } \\
\text { disease }\end{array}$}} & & & \\
\hline & 1 & 1 & 12 & 20 & 8 & 14 & 60 \\
\hline \\
\hline & 3 & 3 & 1 & 1 & 1 & 2 & 83 \\
\hline \multicolumn{8}{|l|}{$\begin{array}{l}\text { Bronchiectasis } \\
\text { Bronchopulmonary }\end{array}$} \\
\hline \multirow{7}{*}{$\begin{array}{l}\text { dysplasia } \\
\text { Solitary cysts \& } \\
\text { solid lesions } \\
\text { Asthma } \\
\text { Foreign body } \\
\text { Miscellaneous } \\
\text { Total no. studied } \\
\% \text { Useful tests }\end{array}$} & 0 & 1 & 4 & 5 & 0 & 0 & 67 \\
\hline & 0 & 1 & $\mathbf{0}$ & 1 & $\mathbf{0}$ & 3 & $\mathbf{0}$ \\
\hline & $\mathbf{0}$ & 0 & 1 & 1 & $\mathbf{0}$ & 2 & 33 \\
\hline & $\mathbf{0}$ & $\mathbf{0}$ & 0 & 2 & 0 & $\overline{1}$ & 0 \\
\hline & 1 & 4 & 7 & 7 & 1 & 2 & 69 \\
\hline & \multirow{2}{*}{\multicolumn{2}{|c|}{44}} & 38 & 55 & 20 & 52 & 123 \\
\hline & & & \multicolumn{2}{|c|}{69} & \multicolumn{2}{|c|}{39} & 53 \\
\hline
\end{tabular}


localized the lesions, they did not provide information that was not available from other investigations (e.g. plain chest $x$-ray). The RLF tests were only useful in one of the 3 asthmatics studied, an 8-monthold baby, in whom we were able to exclude a structural cause for severe, persistent wheezing. They were most useful in the 5 out of 6 children studied with pulmonary agenesis or hypoplasia and it seems that the pattern of a small, normally functioning lung is so characteristic of hypoplasia as to render other investigations unnecessary.

In all other groups RLF studies were considered to be of value in 50 to $70 \%$ of children. The incidence of worthwhile tests depended somewhat on the age of the child and was apparently most useful in the 6-month to 6-year age group (69\% of useful tests), compared with $44 \%$ in younger children and $39 \%$ in older children. A $\chi^{2}$ test on these proportions showed a significant difference $(P<0 \cdot 005)$ between the middle and older group, but not between the middle and younger group $(P=0 \cdot 12)$. The difference in incidence of worthwhile tests partly reflected the fact that other types of lung function tests were not usually applicable in the middle age range. Within some individual clinical groups this age effect is particularly striking. Thus RLF tests were most useful in all 7 children between 6 months and 6 years in the miscellaneous group, in all 4 children with cystic fibrosis, and in nearly all the children with unilateral radiolucent lungs, scoliosis, and bronchopulmonary dysplasia.

The reasons for undertaking the RLF tests in relation to the clinical groups are given in Table 2. The commonest reason was to estimate the severity of known lung disease (36\% of all reasons) which was influenced to some degree by the large group of children with cystic fibrosis. There were almost equal proportions of studies performed to confirm the localized nature of a suspected disorder $(21 \%)$ mainly reflecting the group with unilateral hyperlucent lungs, and studies to detect pulmonary vascular disease $(20 \%$ of total RLFs) -reflecting the substantial cardiac group. RLF tests for the other reasons listed were performed in $10 \%$ or less of cases.

The most useful diagnostic test for each clinical group of patients is given in Table 3. Because in some children more than one test was considered very useful, the overall proportion of tests in which RLF tests was useful ( $42 \%)$ is less than the overall proportion of children in whom RLF tests were useful $(53 \%$, Table 1). Of the wide range of other tests considered, the most frequently helpful were routine lung function tests in older children $(15 \%)$, again reflecting the cystic fibrosis group, and bronchography and angiography ( $10 \%$ each), reflecting the various pulmonary disorders and the cardiac group. In the three groups for whom RLF tests were not thought to help, other tests provided answers to the questions posed.

A comparison between the reasons for undertaking the RLF tests and the most useful test is shown in the Fig. RLF tests were most helpful in answering about 40 to $50 \%$ of each of the questions, except about differential pulmonary blood flow in which case they provided the answer in all 12 children. Bronchography was particularly useful in confirming localized lung disease and angiography in the pulmonary vascular disease group. The generalized pulmonary disease group only contained 5 subjects. It should be noted that in some of the children in this 'reason for test' grouping, more than one test

Table 2 Reasons for undertaking RLF tests

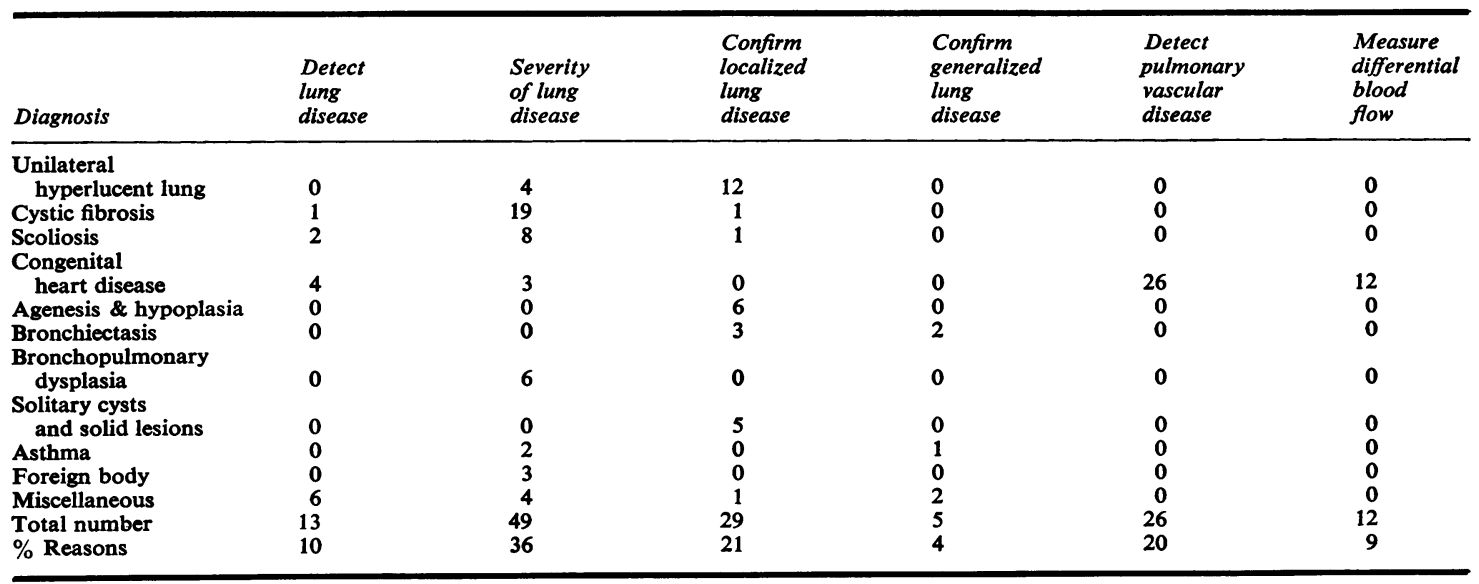


Table 3 Most useful tests in various clinical conditions

\begin{tabular}{|c|c|c|c|c|c|c|c|c|c|c|c|c|c|}
\hline Diagnosis & $R L F$ & $\begin{array}{l}\text { Infant } \\
\text { lung } \\
\text { function }\end{array}$ & $\begin{array}{l}\text { Child } \\
\text { lung } \\
\text { function }\end{array}$ & $\begin{array}{l}\text { Blood } \\
\text { gases }\end{array}$ & $\begin{array}{l}\text { Plain } \\
\text { chest } \\
x \text {-ray }\end{array}$ & $\begin{array}{l}\text { Screen- } \\
\text { ing }\end{array}$ & $\begin{array}{l}\text { Tomo- } \\
\text { graphy }\end{array}$ & $\begin{array}{l}\text { Broncho- } \\
\text { graphy }\end{array}$ & $\begin{array}{l}\text { Angio- } \\
\text { graphy }\end{array}$ & $\begin{array}{l}\text { Broncho- } \\
\text { scopy }\end{array}$ & Biopsy & $\begin{array}{l}\text { Clinical } \\
\text { observation }\end{array}$ & $\begin{array}{l}\text { Bio- } \\
\text { chemistry }\end{array}$ \\
\hline $\begin{array}{l}\text { Unilateral } \\
\text { hyperlucent } \\
\text { lung }\end{array}$ & 8 & 0 & 1 & $\mathbf{0}$ & 1 & $\mathbf{0}$ & 0 & 6 & 2 & 1 & 0 & $\mathbf{0}$ & 0 \\
\hline Cystic & & & & & & & & & & & & & \\
\hline fibrosis & 11 & 2 & 15 & 0 & 10 & $\mathbf{0}$ & $\mathbf{0}$ & $\mathbf{0}$ & $\mathbf{0}$ & $\mathbf{0}$ & 0 & 0 & 1 \\
\hline $\begin{array}{l}\text { Scoliosis } \\
\text { Congenital }\end{array}$ & 6 & 0 & 3 & 0 & 2 & $\mathbf{0}$ & $\mathbf{0}$ & $\mathbf{0}$ & $\mathbf{0}$ & $\mathbf{0}$ & 0 & $\mathbf{0}$ & $\mathbf{0}$ \\
\hline heart disease & 21 & $\mathbf{0}$ & 1 & $\mathbf{0}$ & $\mathbf{0}$ & 0 & 0 & $\mathbf{0}$ & 14 & 0 & 0 & 0 & 0 \\
\hline $\begin{array}{l}\text { Agenesis \& } \\
\text { hypoplasia }\end{array}$ & 5 & $\mathbf{0}$ & 0 & 0 & 0 & 0 & 0 & 2 & 0 & 0 & 0 & $\mathbf{0}$ & 0 \\
\hline $\begin{array}{l}\text { tasis } \\
\text { Broncho- }\end{array}$ & 0 & 0 & 2 & 0 & $\mathbf{0}$ & $\mathbf{0}$ & 0 & 5 & 0 & $\mathbf{0}$ & $\mathbf{0}$ & 0 & 0 \\
\hline $\begin{array}{l}\text { pulmonary } \\
\text { dysplasia }\end{array}$ & 4 & 2 & 0 & $\mathbf{0}$ & 0 & 0 & 0 & 0 & 0 & 0 & 0 & 0 & 0 \\
\hline $\begin{array}{l}\text { Solitary } \\
\text { cysts and }\end{array}$ & & & & & & & & & & & & & \\
\hline $\begin{array}{l}\text { lesions } \\
\text { Asthma }\end{array}$ & $\begin{array}{l}0 \\
1\end{array}$ & $\begin{array}{l}0 \\
0\end{array}$ & $\begin{array}{l}\mathbf{0} \\
\mathbf{0}\end{array}$ & $\begin{array}{l}0 \\
0\end{array}$ & $\begin{array}{l}1 \\
0\end{array}$ & $\begin{array}{l}\mathbf{0} \\
\mathbf{0}\end{array}$ & $\begin{array}{l}3 \\
0\end{array}$ & $\begin{array}{l}2 \\
0\end{array}$ & $\begin{array}{l}\mathbf{0} \\
\mathbf{0}\end{array}$ & $\begin{array}{l}0 \\
0\end{array}$ & $\begin{array}{l}\mathbf{0} \\
\mathbf{0}\end{array}$ & $\begin{array}{l}\mathbf{0} \\
2\end{array}$ & $\begin{array}{l}\mathbf{0} \\
\mathbf{0}\end{array}$ \\
\hline Foreign body & 0 & 0 & 0 & 0 & $\mathbf{0}$ & 0 & 0 & 0 & $\mathbf{0}$ & 3 & 0 & 0 & 0 \\
\hline Miscellaneous & 9 & 3 & 1 & 1 & $\mathbf{0}$ & $\mathbf{0}$ & 0 & 0 & 0 & 0 & $\mathbf{0}$ & 0 & 0 \\
\hline $\begin{array}{l}\text { Total no. } \\
\text { studied } \\
\text { \% Reasons }\end{array}$ & $\begin{array}{l}65 \\
42\end{array}$ & $\begin{array}{l}7 \\
5\end{array}$ & $\begin{array}{l}23 \\
15\end{array}$ & $\begin{array}{l}1 \\
1\end{array}$ & $\begin{array}{r}14 \\
9\end{array}$ & $\begin{array}{l}0 \\
0\end{array}$ & $\begin{array}{l}3 \\
2\end{array}$ & $\begin{array}{l}15 \\
10\end{array}$ & $\begin{array}{l}16 \\
10\end{array}$ & $\begin{array}{l}4 \\
3\end{array}$ & $\begin{array}{l}0 \\
1\end{array}$ & $\begin{array}{l}2 \\
1\end{array}$ & $\begin{array}{l}1 \\
1\end{array}$ \\
\hline
\end{tabular}

was useful so that the total numbers of useful tests in the groups shown in the Fig. exceed the numbers shown in Table 2.

\section{Discussion}

This analysis was carried out in an attempt to define the true place of RLF tests in clinical paediatrics on the basis of our experience with the relatively simple technique which we developed for the purpose. The importance of such an analysis lies in the fact that the investigation delivers a modest but significant dose of radiation to the child, occupies a physician, technician, and physicist each for at least an hour, and would cost about as much as a bronchogram under anaesthesia. The rapidly growing demand for RLF tests by colleagues who have become aware of their potential value has also forced us to try to define more accurately those children in whom the tests are likely to answer specific questions. RLF tests have been applied to children by other investigators in such conditions as cystic fibrosis (Alderson et al., 1974), congenital heart disease (Arborelius et al., 1971; Alderson et al., 1976), and respiratory distress syndrome (Koch et al., 1973), but there has been no previous systematic attempt to establish the clinical value of the tests in a wide selection of patients.

We do not intend to discuss the method here, as we have already presented evidence of its application and validity elsewhere (Godfrey et al., 1975; Winlove et al., 1977; Godfrey et al., 1977). However, we now have a good idea of the range of normal function for both ventilation and perfusion studies, and the comparison of the washout curves from such studies gives a useful estimate of ventilation-perfusion imbalance.

The decision about the value or otherwise of the RLF and other types of test in the present study has had to be somewhat subjective since there is no obvious way of making a quantitative estimate of value. In most cases it was easy to decide whether or not the test provided data of real significance to the management, i.e. diagnosis or prognosis, and in those cases where more than one test provided similar information then the simplest or safest test was usually obvious. For example, both RLF and whole body infant plethysmography can be used to determine whether an infant under 6 months of age has evidence of lung disease in the presence of a normal chest $x$-ray, but in this case the harmless, noninvasive infant plethysmograph technique would obviously be the better test. In a few cases the decision was difficult, especially if they were cardiac patients. Thus in a child with pulmonary hypertension estimated at catheterization, an abnormal RLF test added nothing and yet in other children we found discrepancies between the catheter data and the site or severity of pulmonary vascular disease. In those children the RLF tests were useful and one could argue that they should be carried out in all infants with high pulmonary blood flows to detect pulmonary vascular disease.

The overall incidence of useful RLF tests of $53 \%$ 


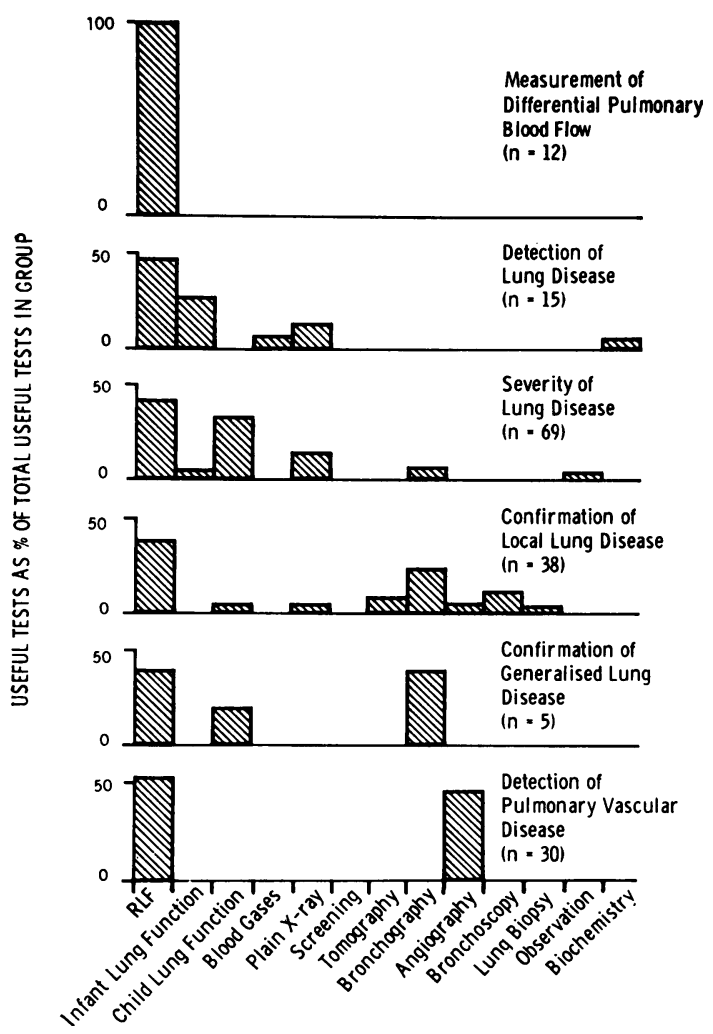

Fig. Proportion of investigations which were found to be useful expressed as a percentage of all useful investigations in studies classified according to the reasons for carrying out $R L F$ tests. In all groups apart from the measurement of differential pulmonary blood flow, RLF tests were the most useful in 40 to $50 \%$ of tests. ( $n=$ number of useful tests in group.)

was encouraging, but leaves room for considerable improvement in selection of patients. The analysis showed that the tests were more likely to be useful in children between 6 months and 6 years of age, because in younger children with generalized disorders, we now have very accurate methods of measuring lung function (Stocks et al., 1977), and in older children we can study cardiopulmonary function at rest and on exercise in considerable detail by noninvasive methods (Polgar and Promadhat, 1971; Godfrey, 1974). RLF tests were carried out to answer a variety of questions, most commonly about the severity or localization of lung disease $(81 \%$ of studies in children with lung disease) and to detect pulmonary vascular disease $(69 \%$ of studies in children with congenital heart disease). The proportion of useful tests was much the same, except for their particular value in measuring differential pulmonary blood flow. An observation which has been made before (Arborelius et al., 1971; Treves et al., 1974).

As a result of these investigations, we now believe it is possible to provide a list of conditions for which RLF tests are generally very useful and this is shown in Table 4. Had we used these criteria for selection,

\section{Table 4 Recommendations}

(A) Conditions in which $R L F$ tests are generally very useful

(i) Unilateral hyperlucent lung, especially in children between 6 months and 6 years

(ii) Cystic fibrosis, in children between 6 months and 6 years, especially any child being considered for pulmonary resection

(iii) Pulmonary vascular disease, which may be developing

(iv) Differential pulmonary blood flow measurement, when this cannot be ascertained during catheterization

(v) Generalized lung disorders, either to detect their presence or evaluate severity in children between 6 months and 6 years

(vi) Pulmonary agenseis or hypoplasia, at any age

(B) Conditions in which RLF tests are sometimes useful

(i) Asthma, in children under 6 years

(ii) Other conditions, as above in older children

(C) Conditions in which RLF tests are rarely useful

(i) Foreign bodies

(ii) Solitary cysts or solid lesions

(iii) Bronchiectasis

(iv) Generalized lung disease, in infants under 6 months or over 6 years

(v) Pulmonary vascular disease, in older children

the proportion of helpful RLF tests in the most useful group would have been $72 \%$, in the occasionally useful group $46 \%$, and in the rarely useful group $14 \%$.

We are grateful to Dr. M. Fitzpatrick and Miss M. Tooley for help in carrying out the radioisotopic lung function tests, and to our colleagues for referring many of the patients studied. The staff of the MRC Cyclotron Unit worked hard to provide ${ }^{13} \mathrm{~N}$ to suit the demands of paediatric patients.

\section{References}

Alderson, P. O., Secker-Walker, R. H., Strominger, D. B., McAlister, W. H., Hill, R. L., and Markham, J. (1974). Quantitative assessment of regional ventilation and perfusion in children with cystic fibrosis. Radiology, 111, 151-155.

Alderson, P. O., Boonvisut, S., McKnight, R. C., and Hartman, A. F. (1976). Pulmonary perfusion abnormalities and ventilation-perfusion imbalance in children after total repair of tetralogy of Fallot. Circulation, 53, 332-337.

Arborelius, M., Gustafsson, T., Kjellman, B., Lundström, N. R., and Mortensson, W. (1971). Xe ${ }^{133}$-Radiospirometry for evaluation of congenital malformations of pulmonary arteries. Pediatrics, 47, 529-536.

Godfrey, S. (1974). Exercise Testing in Children-Applications in Health and Disease. Saunders, London.

Godfrey, S., Ronchetti, R., Stocks, J., and Hallidie-Smith, K. (1975). Generalised pulmonary hyperinflation and Fallot's tetralogy in a neonate investigated by pulmonary physiological and radioisotopic methods. Thorax, 30, $452-460$.

Godfrey, S., Hambleton, G., Winlove, P., and Freedman, N. (1977). Unilateral lung diseases detected by radioiso- 
topic scanning in children thought to have asthma. British Journal of Diseases of the Chest, 71, 7-18.

James, A. E., Wagner, H. N., and Cooke, R. E. (1974). (Editors.) Pediatric Nuclear Medicine. Saunders, Philadelphia.

Kjellman, B. (1967). Regional lung function studied with $\mathrm{Xe}^{133}$ in children with pneumonia. Acta Paediatrica Scandinavica, 56, 467-476.

Koch, G., Heiskanen, T., Riihimäki, E., Lind, J., Tähti, E., and Österlund, K. (1973). Regional distribution of ventilation and perfusion in the healthy newborn infant and in the idiopathic respiratory distress syndrome. Bulletin Européen de Physiopathologie Respiratoire, 9, 1511-1532.

McKenzie, S. A., MacArthur, C. G. C., Godfrey, S., and Hallidie-Smith, K. A. (1977). Hypertensive pulmonary vascular disease in children: detection by radioactive nitrogen $\left({ }^{13} \mathrm{~N}\right)$ inhalation and injection. British Heart Journal, 39, 866-871.

Polgar, G., and Promadhat, V. (1971). Pulmonary Function Testing in Children. Saunders, Philadelphia.
Ronchetti, R., Stocks, J., Freedman, N., Glass, H., and Godfrey, S. (1975). The clinical application of regional lung function studies in infants and small children using ${ }^{13}$ N. Archives of Disease in Childhood, 50, 595-603.

Stocks, J., Levy, N. M., and Godfrey, S. (1977). A new apparatus for the accurate measurement of airway resistance in infancy. Journal of Applied Physiology, 43, 155-159.

Treves, S., Ahnberg, D. S., Laguarda, R., and Strieder, D. J. (1974). Radionuclide evaluation of regional lung function in children. Journal of Nuclear Medicine, 15, 582-587.

Winlove, P., Freedman, N., Fitzpatrick, M. L., and Godfrey, S. (1977). The quantitation of regional lung function in infants and children using radioactive nitrogen $\left({ }^{13} \mathrm{~N}\right)$. Submitted for publication.

Correspondence to Prof. S. Godfrey, Department of Pediatrics, Hadassah University Hospital, Mount Scopus, Jerusalem, Israel. 